\title{
SWAT modeling of the soil properties in GIS- environment: initial calculations
}

\author{
Ielizaveta Dunaieva ${ }^{1}$, Valentina Popovych $^{1}$, Aleksandr Melnichuk $^{2}$, Wilfried Mirschel $^{3}$, \\ Vitaly Terleev ${ }^{4}$, Aleksandr Nikonorov ${ }^{4, *}$, Issa Togo $^{4}$, Yulia Volkova ${ }^{4}$, and Dmitry Shishov ${ }^{5}$ \\ ${ }^{1}$ Federal State Budget Scientific Institution «Research Institute of Agriculture of Crimea», Kievskaya, \\ 150, Simferopol, Crimea, 295453, Russia \\ ${ }^{2}$ V.I.Vernadsky Crimean Federal University, Vernadskogo pr., 4, Simferopol, Crimea, 295007, Russia \\ ${ }^{3}$ Leibniz-Centre for Agricultural Landscape Research, Eberswalder Straße 84, Müncheberg, 15374, \\ Germany \\ ${ }^{4}$ Peter the Great St.Petersburg Polytechnic University, Polytechnicheskaya, 29, St.Petersburg, 195251, \\ Russia \\ ${ }^{5}$ St.Petersburg State Agrarian University, Peterburgskoye shosse, 2, St. Petersburg-Pushkin, 196601, \\ Russia
}

\begin{abstract}
The problem of soil parameters modeling and input data preparation are considered in the article. The use of Soil and Water Assessment Tool was analyzed. The question of the soil water content and basic soil agronomic characteristics was considered. The SWAT project was created for the period of 2014-2017 years and could be prolonged. A soil map and cartographic information were digitized for the analysis of soil characteristics. An assessment of soils moisture absorption in different key areas was made in the course of the research.
\end{abstract}

\section{Introduction}

The study of processes occurring in the soil, soil characteristics, soil moisture reserves level, etc. is an essential element for predicting the yield of crops, determining the limiting factors influencing the formation of biomass.

Agro-hydrological and other computational models, which are used in the agricultural plants development modeling, contain soil information of a different volume and specification, which is determined not only by the analytical model calculating scheme (single-layer or multilayered) but also by the principle of its implementation in space (2D or 3D). Soil characteristics, which are used in the SWAT model, are divided into 2 groups: physical and chemical. Physical characteristics are necessary for the modeling of water movement along the soil profile. These characteristics play an important role in the water cycle within the single-type key areas or Hydrologic Response Units (HRUs). Chemical characteristics are used for definition of the various chemical elements level in the soil.

\footnotetext{
* Corresponding author: coolhabit@yandex.ru
} 
Results of soil parameters modeling were analyzed in current study concerning the territory of Crimea, the results of the flow modeling were observed in other articles [1-3]. The Soil and Water Assessment Tool (SWAT) is a river basin, or watershed, scale model developed by Dr. Jeff Arnold for the USDA Agricultural Research Service (ARS). SWAT was developed for the prediction of the impact of land management activities on the water, as well as the impact of the sediment and agricultural chemical yields in large complicated watersheds with varying types of soils, land use and management conditions over the long periods of time [4].

The SWAT model was originally built by the algorithm, which uses $3 \mathrm{D}$ characteristics of the Earth's surface to realize the tasks of moisture and water streams movement, taking into account the gradients and slopes of the surface. Soil characteristics in the model are given through the spatial distribution of the soils (in the form of a digital map) and their respective characteristics are recorded in the database [4].

All the simulation was held in the GIS environment (ArcGIS or MapWindow) [5]. Use of the GIS software gives possibility to run a model, which could include different aspects and different time steps, such as day, month and year, could be set.

\section{Materials and Methods}

The large amount of source information that has point or spatial geobridging was used for the dynamics of soil characteristics modeling. Available external data sources [1] could be used for the preliminary calculations, including the layer of soil information with the corresponding databases of soil characteristics.

The following input data was used for the modeling process initialization: a) digital elevation model (DEM), with 90 m resolution; b) land use and soil maps; c) weather data, including maximum and minimum air temperature $\left(\mathrm{C}^{\circ}\right)$, precipitation $(\mathrm{mm} /$ day $)$, wind speed $(\mathrm{m} / \mathrm{sec})$, solar radiation $(\mathrm{MJ} / \mathrm{m} 2)$, relative humidity (fractional) and potential evapotranspiration ( $\mathrm{mm} /$ day).

Agricultural lands, located on the territory of the Klepininsky rural council of Krasnogvardeisky district of the Republic of Crimea were considered as the research area.

According to the agroclimatic zoning of the Republic of Crimea, the territory of Krasnogvardeysky district and the study area are belonging to the central - steppe agroclimatic region. Land use structure of the territory is presented on the Figure 1.

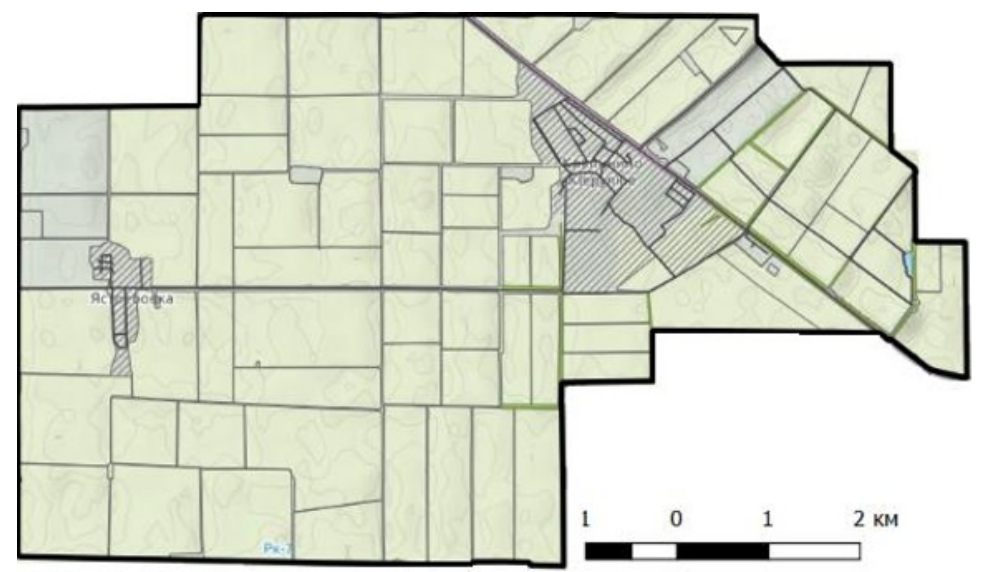

Fig. 1. Land use structure of the study area. 
Clayey chernozems are dominating among the southern chernozems of the Krasnogvardeysky region, for which the soil-forming rocks are the loess-like deposits. The granulometric composition of the loess-like clays varies from the light clay to medium-clay. Quaternary loess-like clays of the medium-grained granulometric composition contain 78.0$78.2 \%$ of physical clay particles; silt fraction - 46.0-46.1\%. Light-clayey loess-like clays contain $61.5-71.6 \%$ of physical clay particles, clay fraction - 31.7-44.2\%. Loess-like loams are characterized by the heavy loam granulometric composition. These loams contain 40.8$64.6 \%$ of the physical clay particles, and $16.8-34.0 \%$ of the clay fraction in a $120-150 \mathrm{~cm}$ layer [6].

Loess-like clays are divided into saline and non-saline by the degree of the salinity. Gypsum prevails in the composition of salts. Its first level could be marked at the depth of $150-200 \mathrm{~cm}$, situationally $-80-150 \mathrm{~cm}$. The dense residue in the gypsum horizon varies within the range of $0.073-1.250 \%$. The presence of a small amount of toxic salts could sometimes be observed [7, 8].

Available cartographic information was used to clarify the regional parameters and boundaries of the soil differences. An example of the vector map of soil grounds for the territory of the experimental farm of the FSBSI "RIA of Crimea", obtained on the basis of a digitized soil map 1: 200000 (Map of Ukraine, Ukraine, 1967), is shown in Figure 2.

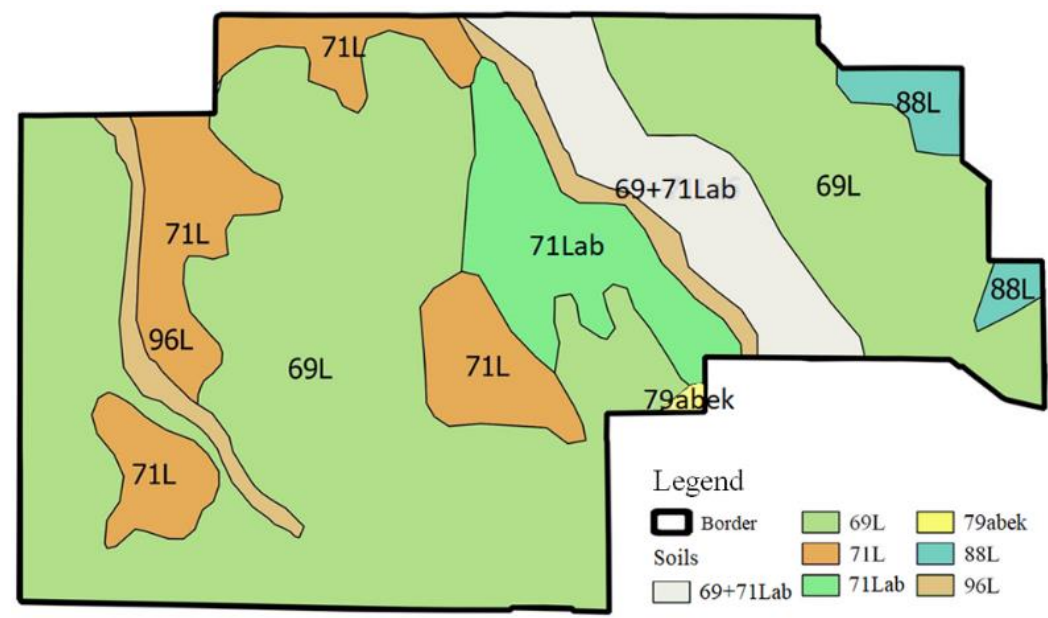

Fig. 2. Soil map of the territory (created on the basis of the map M 1:200000).

where: 69- southern low-humus chernozem; 71- southern low-humus micellar-highcarbonate chernozem; 79- chernozem mainly carbonate gravel and gravel on eluvium of dense and gravel carbonate and carbonized rocks; 88- southern chernozem weakly and medium solonetsous: 96-meadow- chernozem carbonate soils; L-loess and loess-like rocks, a-weakly washed, b- medium washed; ek-eluvium of dense carbonate rocks.

Partial information about the soil characteristics of the Crimea, including the soils of the former Crimean State Experimental Agricultural Station, is available in the literature and the reference publications (for example [9, 10]).

The staff of the GIS technology laboratory in cooperation with the specialists of the Dokuchaev Soil Science Institute selected the soil samples from the areas for the laboratory refinement of water-physical parameters, and conducted field studies of these soils absorbency to clarify the number of soil characteristics parameters that was used in the model. 
During the united field research in 2016 under the guidance of Dr. Sc. N.B. Khitrov, the head of the department of genesis and melioration of saline and solonetz soils, additional research of the water permeability of the soils, using the tube method, was carried out [11]. Water permeability research was done both on the soil cross-sections, studied by the Soil Institute with the preparation of special sites at a depth of 15 to $60 \mathrm{~cm}$, and on separately created cross-sections (see Figure 3).

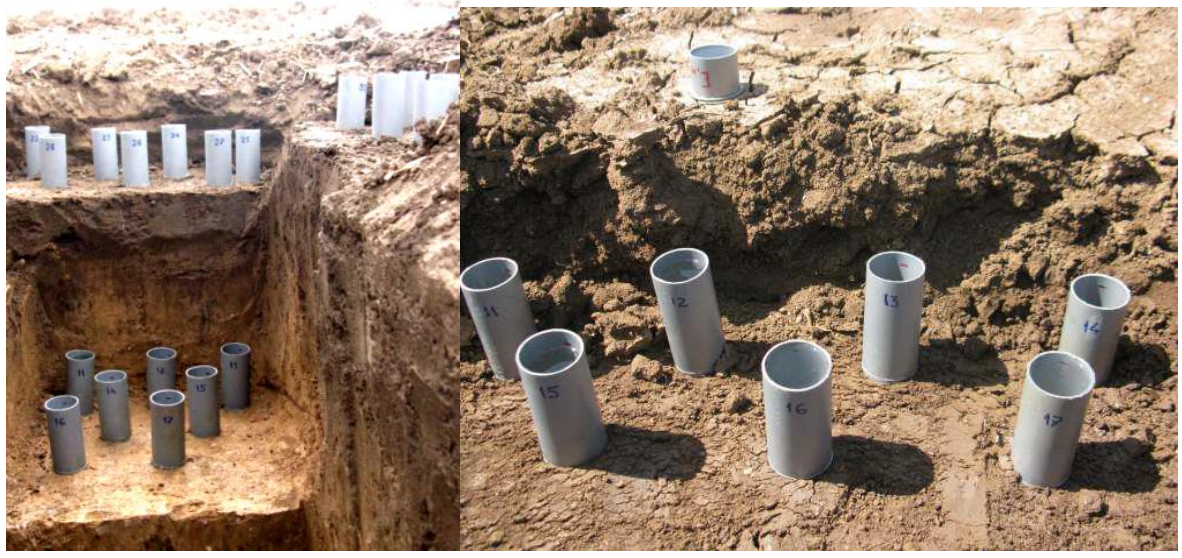

Fig. 3. Elements of tube method application for measuring of water permeability characteristics of various soil layers $\left(45^{\circ} 32^{\prime} 10.6^{\prime \prime} \mathrm{N} 34^{\circ} 11^{\prime} 38.0^{\prime \prime} \mathrm{E}\right.$; 05.08.2016, Klepininsky settlement territory, Krasnogvardeysky district).

In the first step, the prepared data was imported and processed. In the next step, the imported data processing was done using the GIS software (Figure 4). After the creation of the separate project within the SWAT interface, modeling was continued with Watershed delineation tab. A detailed description of the data loading and processing stages was considered in the article [2].

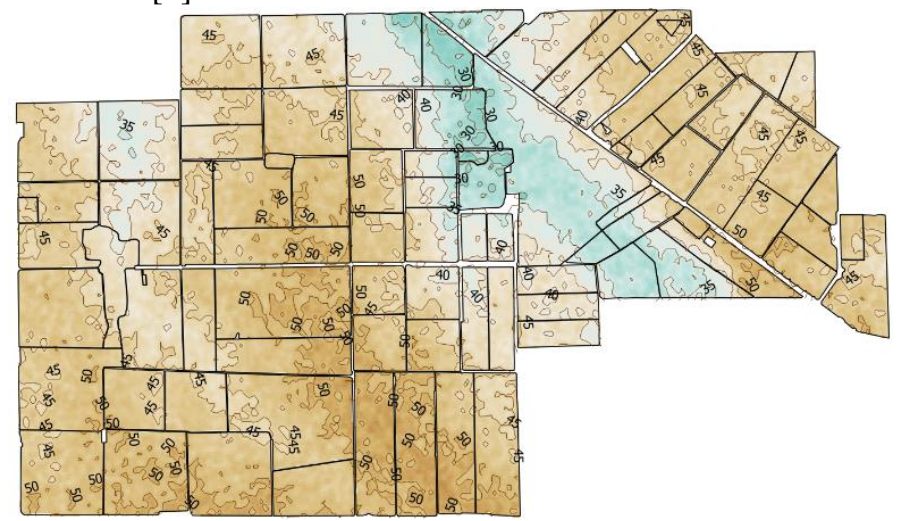

Fig. 4. DEM and watershed delineation.

Land use data was prepared in shape-file format and then was converted to the raster format with the identification of the land use type in SWAT DB (Figure 5). 


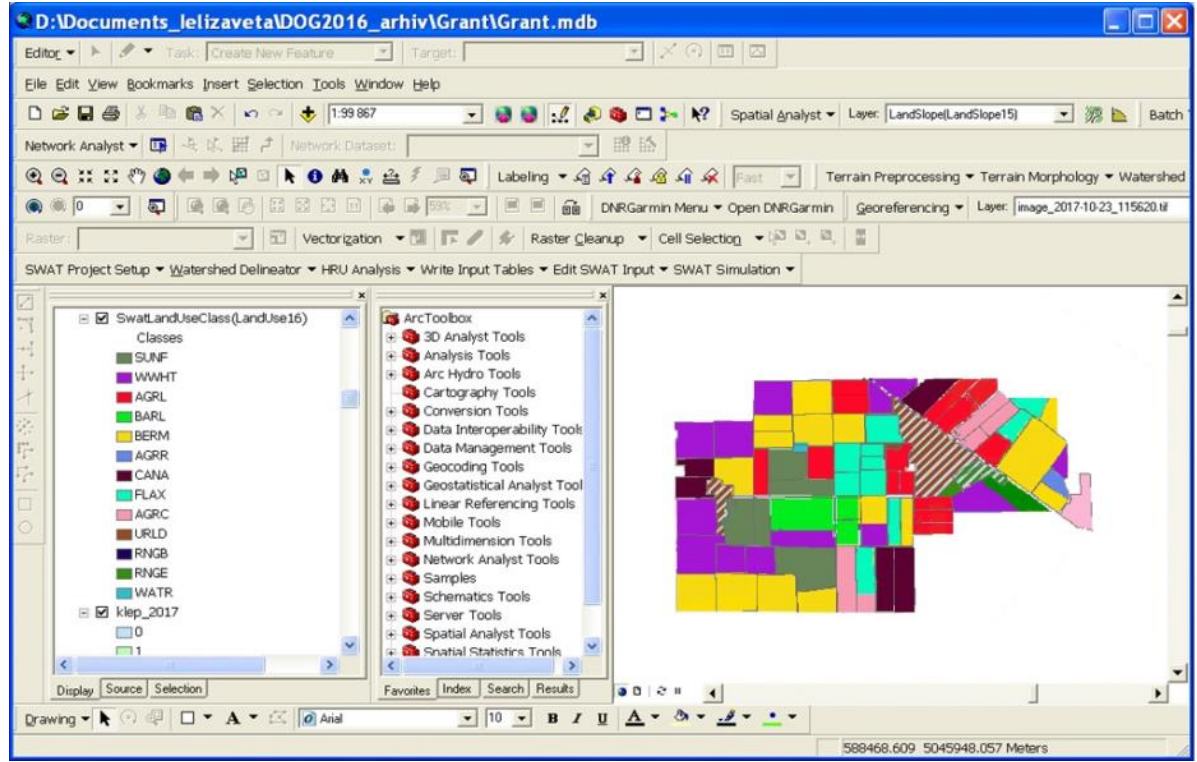

Fig. 5. LandUseData processing.

Soil data was obtained from the open source [12] and was corrected by the real physical and chemical characteristics of soils (Figure 6).

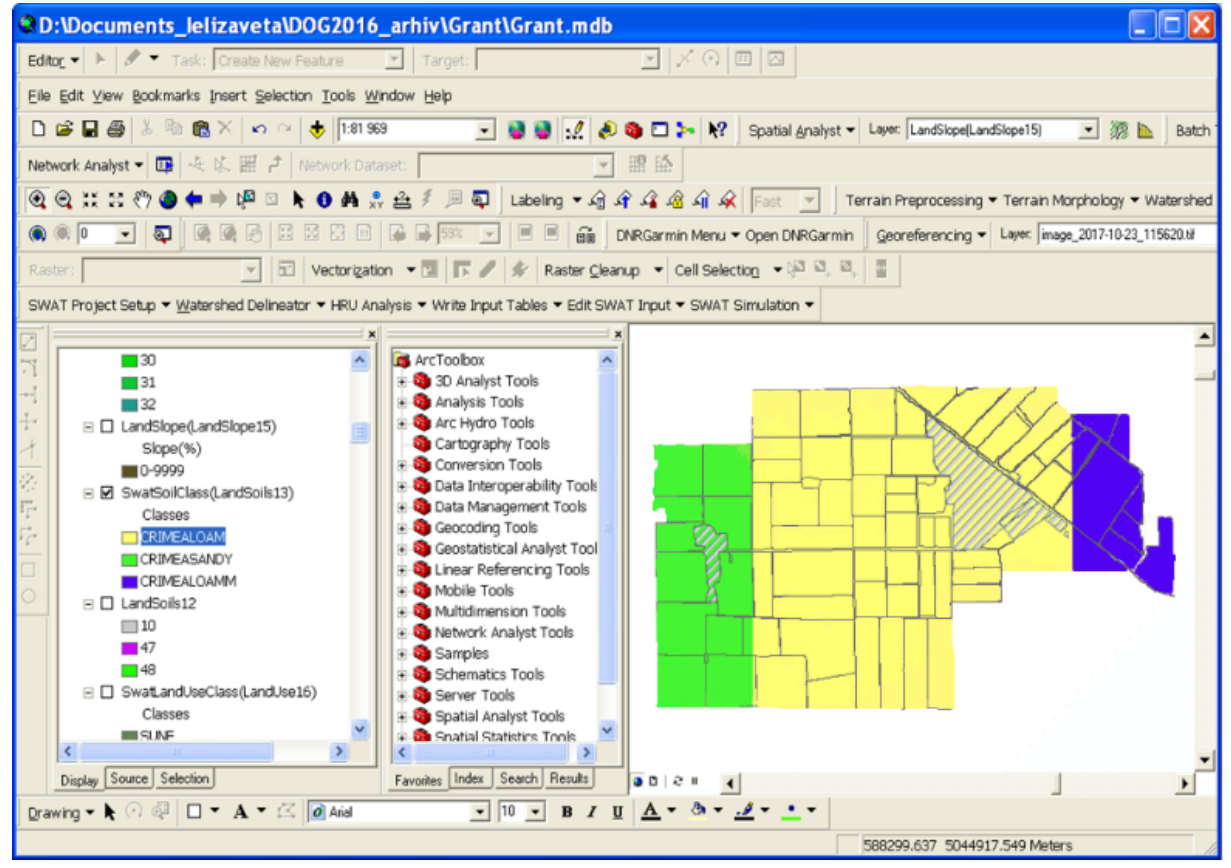

Fig. 6. Soil Data processing.

Table 1 shows the structure of the Soil DB with soil characteristics, which was used in the SWAT model. 
Table 1. Structure of the Soils DB in the SWAT model.

\begin{tabular}{|l|l|l|l|l|l|}
\hline No. & Field Name & Type & Size & Accuracy & Description \\
\hline 1 & ID & Integer & 6 & 0 & ID number in the database \\
\hline 2 & N_Soil & Integer & 10 & 0 & soil type \\
\hline 3 & Name_Soil & String & 200 & 0 & name \\
\hline
\end{tabular}

HRU definition was the next step of the research after the watershed, land use and soil parameters loading and refinement. The dominant type of selection was used in this research. Land use, the majority soil and slope of the areas were chosen for each HRU characteristics (Fig. 7).

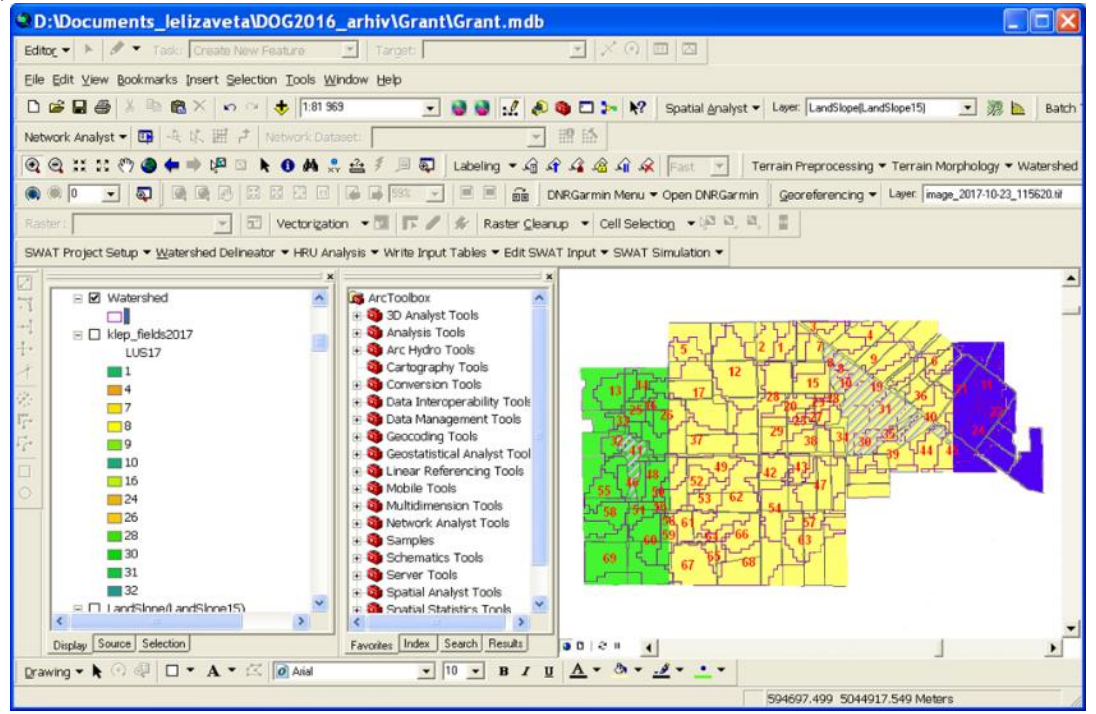

Fig. 7. Soil types for Crimea.

The example of the SWAT model run procedure for the period of 01/01/2014 09/30/2017 is presented below (Figure 8 and 9).

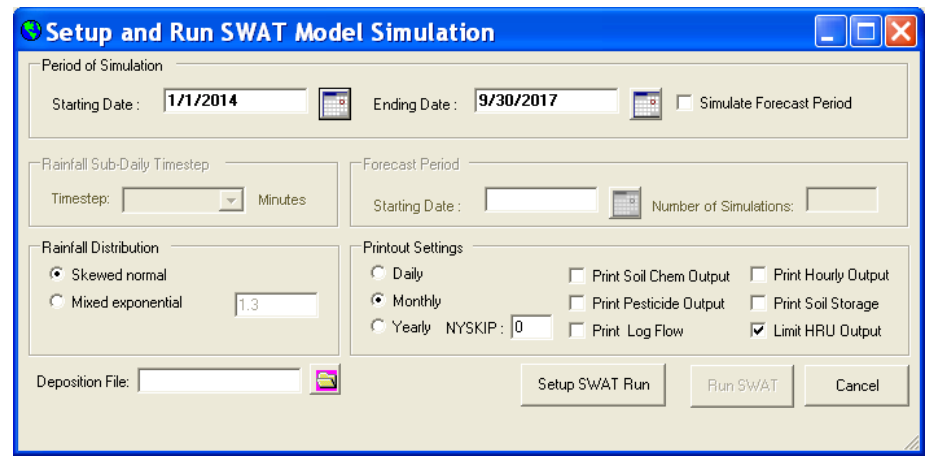

Fig. 8. Run procedure.

Output modeling files were saved as the text and geodatabase files. Text files are more convenient for the further refinement of the simulation results. The month was set as a time step of the run. 


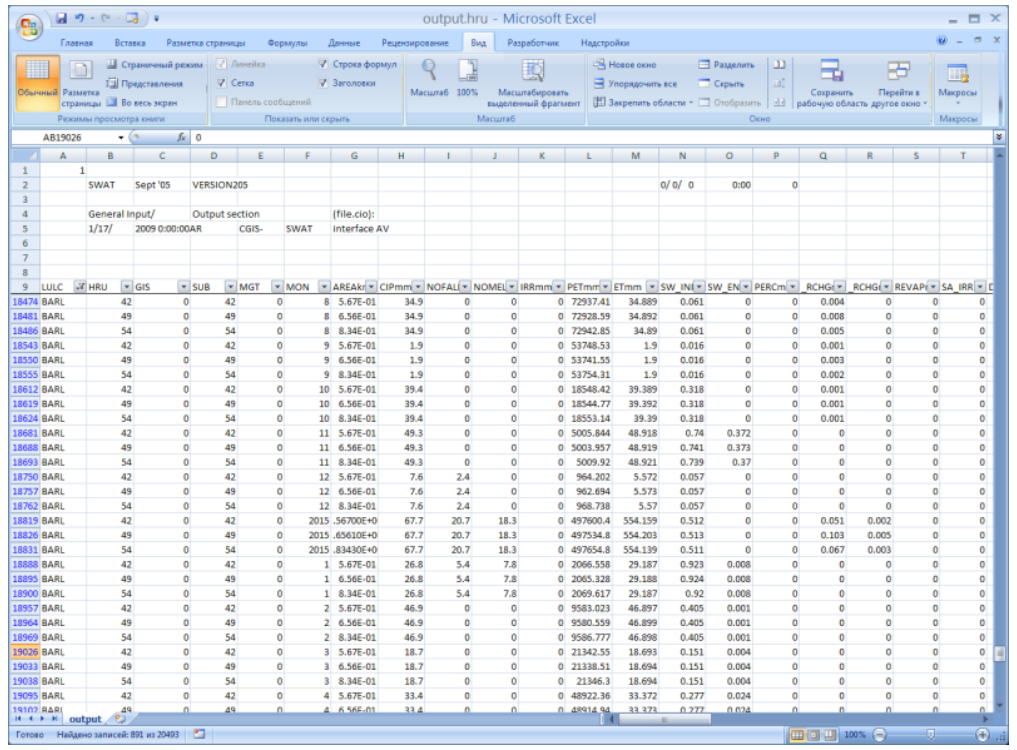

Fig. 9. Output data in Excel-format.

\section{Results and discussions}

An example of the water permeability measurement data variation obtained for the one of the sites is shown in Figure 10. The depth of the layer on the territory of Klepininsky council, Krasnogvardeysky region is $30 \mathrm{~cm}$ from the soil surface.

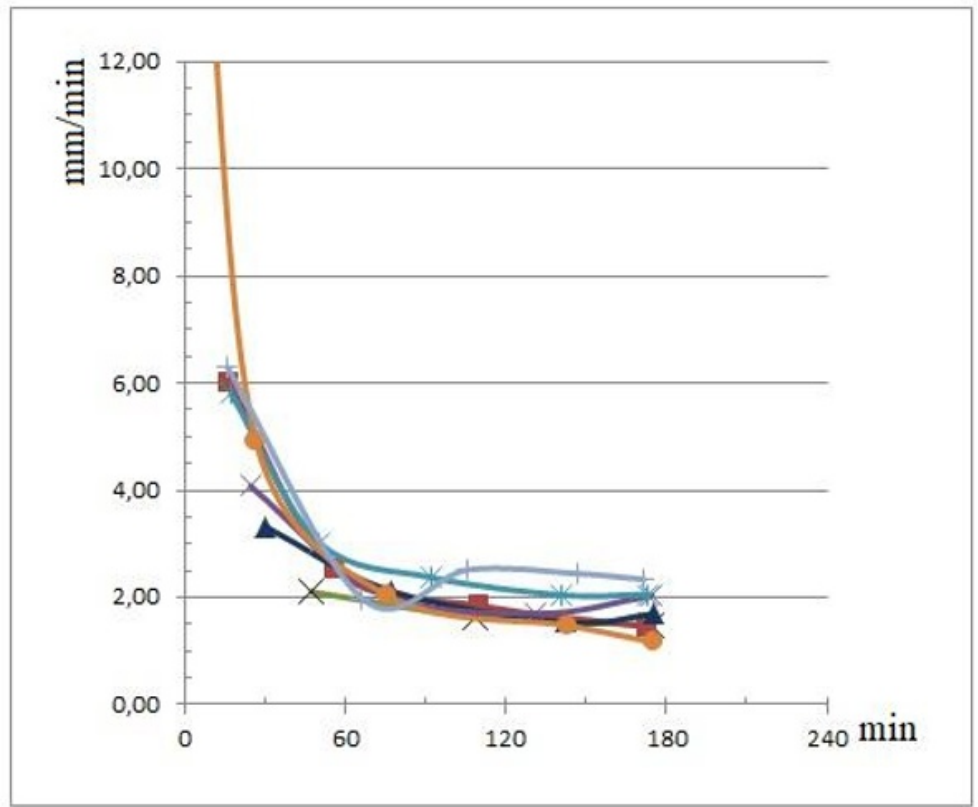

Fig. 10. An example of the curves of dependence of absorption rate on time. 
Results of soil water content simulation with the field data showed that $\mathrm{R}=0,9$.

Table 2. Results of soil water content simulation.

\begin{tabular}{|c|c|c|c|c|}
\hline Name of the culture & N-NO3, field data & N-NO3 & P2O5, field data & P2O5 \\
\hline Spring Barley & 2.33 & 2.04 & 7.60 & 8,47 \\
\hline Winter wheat & 1.78 & 1.44 & 12.01 & 7.78 \\
\hline
\end{tabular}

Results of $\mathrm{P}$ and $\mathrm{N}$ simulation should be corrected with initial fertilize application: types, amounts and dates of operations. The future studies should consider the extension of this research with the use of that data. The proposed method is applicable for another soil properties research, especially hydrophysical properties of the soils [13-17] (water-retention capacity [18-20] and its hysteresis) [21, 22].

\section{Conclusions}

The simulation of soil properties for the rural areas was analyzed. Results of modeling showed possibility of SWAT model usage for the studding water and chemicals transmission in the soil. The methodology could be applicable for the prediction of crop productivity. This research will be extended in the future studies.

\section{Acknowledgements}

The research was carried out as part of theme \#0834-2015-0015 and supported by Russian Foundation for Basic Research (\#16-04-01473-a).

\section{References}

1. Ie.A. Dunaieva, V.F. Popovych, V.M. Paniutin, NUWMNRU, 3(55), $85-92$ (2011).

2. Ie. Dunaieva, International Journal of Engineering Research \& Technology (IJERT), 2(9), 2162- 2167 (2013).

3. Ie.A. Dunaieva, Hydrotechnical amelioration, land reclamation, 99, 249-257 (2011).

4. S.L. Neitsch, J.G. Arnold, J.R. Kiniry, R. Srinivasan, J.R. Williams, Grassland, Soil and Water Research Laboratory of Agricultural Research Service and Blackland Research Centre of Texas Agricultural Experiment Station, 541 (2004).

5. J.G. Arnold, J.R. Kiniry, R. Srinivasan et al, Texas Water Resources Institute, 650 (2013).

6. N.N. Dzens-Litovskaya, Leningrad: Nauka, 157 (1970).

7. Yu.E. Kizyakov, G.E. Tronza, Bulletin of Kharkiv NAU named after. V.V. Dokuchaev, 1, 144-149 (2002).

8. Yu.E. Kizyakov, G.E. Tronza, Materials of the International Scientific Conference, 2, 221-224 (2002).

9. I.Ya. Polovitsky, P. Gusev, Reference book. Simferopol: Tavria, 152 (1987).

10. V.P. Gusev, V.T. Kolesnychenko,. Proceedings of the Crimean state complex agricultural experimental station. Simferopol: Krymizdat, 1, 11-25 (1955).

11. A.F. Vadunin, Z.A. Korchagina, Moscow: Agropromizdat, 416 (1986). 
12. WaterBase project: data from http://www.waterbase.org/resources.html (06/18/2018).

13. V.V. Terleev, A.O Nikonorov, I. Togo, Yu.V. Volkova, R.S. Ginevsky, V.A. Lazarev, E.R. Khamzin, V.V. Garmanov, W. Mirschel, L.I. Akimov, Magazine of Civil Engineering, 70(2), 84-92 (2017).

14. V.V. Terleev, A.O Nikonorov, R.S. Ginevsky, V.A. Lazarev, I. Togo, A.G. Topaj, K.G. Moiseev, V.A. Pavlova, K.A Layshev, M.V. Arkhipov, A.Yu. Melnichuk, I.A. Dunaieva, W. Mirschel, Magazine of Civil Engineering, 77(1), 141-148 (2018).

15. V.V. Terleev, A.G. Topazh, W. Mirschel, Russian Meteorology and Hydrology, 40(4), 278-285 (2015).

16. V. Terleev, R. Ginevsky, V. Lazarev, A. Nikonorov, I. Togo, A. Topaj, K. Moiseev, E. Abakumov, A. Melnichuk, I. Dunaieva, IOP Conference Series: Earth and Environmental Science, 90, Article ID 012105 (2017).

17. A. Nikonorov, S. Pavlov, V. Terleev, N. Arefiev, V. Badenko, Yu. Volkova, Procedia Engineering, 117, 258-263 (2015).

18. A. Makarov, A. Mihailova, N. Arefiev, S. Pavlov, T. Chashchina, V. Terleev, V. Badenko, Procedia Engineering, 117, 225-231 (2015).

19. N. Arefiev, V. Badenko, A. Nikonorov, V. Terleev, Yu. Volkova, Procedia Engineering, 117, 20-25 (2015).

20. N. Arefiev, V. Garmanov, V. Bogdanov, Yu. Ryabov, V. Terleev, V. Badenko, Procedia Engineering, 117, 26-31 (2015).

21. V.V. Terleev, W. Mirschel, U. Schindler, K.-O. Wenkel, Journal International Agrophysics, 24(4), 381-387 (2010).

22. S. Medvedev, A. Topaj, V. Badenko, V. Terleev, IFIP Advances in Information and Communication Technology, 448, 252-261 (2015). 